Eva C. Bunk, Hans-Georg König, Jochen H.M. Prehn and Brian P. Kirby*

\title{
p53 upregulated mediator of apoptosis (Puma) deficiency increases survival of adult neural stem cells generated physiologically in the hippocampus, but does not protect stem cells generated in surplus after an excitotoxic lesion
}

https://doi.org/10.1515/jbcpp-2020-0109

Received April 21, 2020; accepted October 9, 2020;

published online November 9, 2020

\section{Abstract}

Objectives: Neurogenesis occurs in the mammalian brain throughout adulthood and increases in response to metabolic, toxic or traumatic insults. To remove potentially superfluous or unwanted neural stem cells/ neuronal progenitors, their rate of proliferation and differentiation is fine-tuned against their rate of apoptosis. Apoptosis requires the transcriptional and posttranslational activation of Bcl-2-homolgy domain 3 (BH3)only proteins. Previously, we demonstrated that the BH3-only protein p53-upregulated mediator of apoptosis (Puma) controls the physiological rate of apoptosis of neural precursor cells in the adult mouse hippocampus. Puma's role in controlling a lesion-induced increase in neural stem cells is currently not known.

Methods: We employed a model of local, N-methylD-asparte (NMDA)-induced excitotoxic injury to the CA1 hippocampal subfield and immunofluorescence labelling to produce increased neural stem cell proliferation/

\footnotetext{
*Corresponding author: Brian P. Kirby, School of Pharmacy and Biomolecular Sciences, RCSI University of Medicine and Health Sciences, 123 St Stephen's Green, Dublin 2, Ireland, Phone: +3531 4025121, E-mail: bkirby@rcsi.ie. https://orcid.org/0000-0001-9056$830 \mathrm{X}$

Eva C. Bunk, Department of Physiology and Medical Physics, RCSI University of Medicine and Health Sciences, Dublin 2, Ireland; and Klinik für Neurochirurgie, Universitätsklinikum Münster, AlbertSchweitzer-Campus 1, Gebäude A1, 48149, Münster, Germany Hans-Georg König, Department of Physiology and Medical Physics, RCSI University of Medicine and Health Sciences, Dublin 2, Ireland Jochen H.M. Prehn, Department of Physiology and Medical Physics, RCSI University of Medicine and Health Sciences, Dublin 2, Ireland; and Future-Neuro SFI Research Centre, RCSI University of Medicine and Health Sciences, Dublin 2, Ireland
}

neurogenesis in the dentate gyrus at two survival times following the excitotoxic lesion.

Results: Deletion of puma failed to rescue any NMDA-induced increase in adult born cells as assessed by BrdU or Doublecortin labelling in the long-term. No difference in the proportion of BrdU/NeuN-positive cells comparing the different genotypes and treatments suggested that the phenotypic fate of the cells was preserved regardless of the genotype and the treatment.

Conclusions: While neurogenesis is up-regulated in puma-deficient animals following NMDA-induced excitotoxicity to the hippocampal CA1 subfield, puma deficiency could not protect this surplus of newly generated cells from apoptotic cell death.

Keywords: apoptosis; Bcl-2 family; BH3 only proteins; dentate gyrus; hippocampus; neurogenesis.

\section{Introduction}

A remarkable number of new cells are generated every day by neurogenesis in the adult hippocampus of rodents, but their fate seems to be limited by apoptotic cell death. Greater than $60 \%$ of newly formed neurons die by apoptosis [1, 2]. Members of the Bcl-2 protein family and the mitochondrial apoptosis pathways play a critical role in cell death of adult generated cells within the dentate gyrus (DG) $[3,4]$. Apoptosis is triggered through the release of caspase-activating factors from mitochondria, a process initiated through Bax oligomerization. bax-deficient mice display not only reduced apoptosis in the hippocampal neurogenic region but also an increased number of mature DG cells [1]. Functional deficiencies [3], but also cognitive improvements resulted from these aberrantly surviving neurons [5]. Constitutively-activated Bax plays an important role for apoptosis in neural progenitors [6]. Conversely, overexpression of the anti-apoptotic protein $\mathrm{Bcl}-2$, an inhibitor of Bax, significantly decreased apoptotic 
cell death in the granule cell layer (GCL) of the DG and also led to an increased total number of granule cells [7].

However, the exact requirements, mechanisms and signalling cascades in Bax involvement and apoptosis activation in neural stem cells (NSCs) are largely unknown. Bax activation necessitates the transcriptional and posttranslational activation of Bcl-2-homolgy domain 3 (BH3)only proteins that are integrated into several stressactivated signalling pathways. p53-regulated mediator of apoptosis (Puma) is a transcriptional target of p53 and one of the most potent BH3-only proteins [8]. Puma directly activates Bax and neutralizes the activity of all known antiapoptotic Bcl-2 family proteins. Our previous work showed that under physiological conditions the lack of Puma rescued neural precursor cells (NPC) in the hippocampus from apoptotic cell death suggesting these proteins contribute to controlling the fate of newly generated cells within this neurogenic region of the adult brain [9].

Enhanced or reduced rates of neurogenesis occur under certain physiological or pathophysiological conditions. Enriched environment [10], physical activity [11] or antidepressant medication [12] positively regulate hippocampal neurogenesis. Excitotoxic injury [9, 13, 14], global and focal brain ischaemia $[15,16]$, and traumatic brain injury $[17,18]$, all characterized by increased release of the $\mathrm{N}$-methyl-D-aspartate (NMDA) receptor agonist glutamate, stimulate neurogenesis in a process believed to facilitate repair. Conversely, stress [19] and aging [20] reduce the generation of new neurons.

The role of Puma in controlling pathophysiological alterations in adult neurogenesis is largely unknown. Puma was previously shown to rescue neural stem cells from physiological cell death [9]. Furthermore, Liu et al. (2010) showed that stem cell depletion within the DG of p53 knockin mice, a model of genotoxic stress during aging, could be rescued by the deficiency of puma [21]. However, despite this, the role of Puma in precursor cell survival in vivo following excitotoxic injury remains largely uncharacterized. Hippocampal injection of NMDA provides a model of excitotoxic injury and causes pronounced degeneration of CA1 neurons, a model we previously established [22]. We therefore set out to explore the role of Puma in the regulation of neurogenesis following NMDA-induced excitotoxic injury to the mouse hippocampus.

\section{Materials and methods}

\section{Animals}

Animals were housed in individually-ventilated cages (five per cage), with standard sawdust bedding. Ad libitum access to standard food and water and a light/dark cycle of $12 \mathrm{~h}$ was maintained (lights on at $7 \mathrm{am})$. Male mice $(\mathrm{n}=20)$ of the same genetic background $(\mathrm{C} 57 \mathrm{BL} / 6)$ were used in this study, aged 10 weeks, a total number of 10 male puma $^{-/-}$mice and wild-type (wt) animals. Gene-deficient animals were provided by Prof Andreas Strasser (Walter \& Eliza Hall Institute of Medical Research, Melbourne, Australia) and genotyped as previously described [23]. C57BL/6 blastocysts were injected with ES cell clones and mice were back-crossed into the $\mathrm{C} 57 \mathrm{BL} / 6$ background. Bruce $4 \mathrm{ES}$ cells were used to generate the puma knockout animals. Animal experiments were carried out under license from the Department of Health and Children (Ireland) and procedures were reviewed and approved by the Institutional Research Ethics Committee (REC134).

\section{Stereotaxic injection of NMDA and BrdU administration}

Surgical procedures were completed as previously published [14]. NMDA $(10 \mathrm{mg} / \mathrm{ml})$ was dissolved in phosphate-buffered saline (PBS) for the injection. Two groups of $10 \mathrm{puma}^{-/-}$and wt mice each underwent surgery. Six mice per group received intrahippocampal NMDA, and four mice per group received vehicle. Mice were anaesthetized via intraperitoneal (i.p.) injection of $20 \mathrm{mg} / \mathrm{kg}$ Avertin (100 g 2,2,2-tribromoethanol in $62 \mathrm{~mL}$ tert-amyl alcohol) and placed into a stereotaxic frame. Craniectomy was completed according to coordinates measured from Bregma (anterior-posterior $=-1.9 \mathrm{~mm}$, mediallateral $=+/-1.5 \mathrm{~mm}$ ), following a midline incision. Prior to and after injection the needle was tested to exclude a potential block of the cannula. The injection needle was placed into the brain using a dorsal-ventral coordinate of $-1.2 \mathrm{~mm}$ from the brain surface. NMDA (or vehicle) was administered at a rate of $0.1 \mu \mathrm{L} / \mathrm{min}$. Following withdrawal of the needle, the incision was sutured and animals monitored until recovered from the anaesthetic.

Following surgery, we assessed the incorporation of BrdU into newly synthesized DNA. 5-Bromo-2-deoxyuridine (BrdU, $50 \mathrm{mg} / \mathrm{kg}$; Sigma-Aldrich, Ireland) was administered, via the intraperitoneal route, at day 6-9 after NMDA or vehicle administration [9]. which represents the time of peak neurogenesis after excitotoxic insult [14]. To quantify the BrdU-positive cells generated and their survival, animals were sacrificed either one day after the last BrdU treatment (short-term survival group) or seven days after BrdU administration (long-term survival group) (Schematic Figure 1).

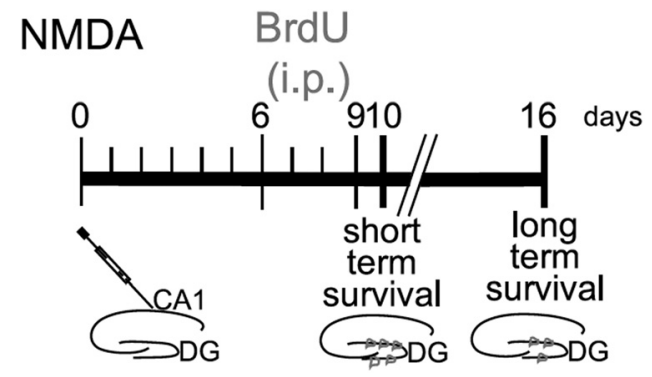

Figure 1: Schematic of experimental regimen. Mice were injected intrahippocampally with NMDA $(10 \mathrm{mg} / \mathrm{mL})$ or saline. Following a recovery period, the mice received $50 \mathrm{mg} / \mathrm{kg}$ of BrdU (days 6-9 following excitotoxic injury). Following an additional $24 \mathrm{~h}$ (day 10 after surgery) or an additional week (day 16 after surgery) mice were sacrificed for subsequent procedures. 


\section{Tissue preparation}

Animals were terminally anaesthetised (sodium pentobarbitone) and transcardially perfused with $20 \mathrm{~mL}$ ice-cold PBS followed by $20 \mathrm{~mL} 4 \%$ PFA (perfusion rate $4 \mathrm{~mL} / \mathrm{min}$ ). Following removal, brains were postfixed in $4 \%$ PFA for $12 \mathrm{~h}$ at $4{ }^{\circ} \mathrm{C}$, cryo-protected in $30 \%$ sucrose/PBS until equilibrated, and frozen at $-20{ }^{\circ} \mathrm{C}$. Long-term storage was at $-80^{\circ} \mathrm{C}$. For immunolabelling, brains were sliced into $10 \mu \mathrm{m}$ coronal sections on a cryostat at $-20{ }^{\circ} \mathrm{C}$ (Leica, Germany). Collection was initiated at an anterior-posterior coordinate of $-1.4 \mathrm{~mm}$ from Bregma. Every $40 \mu \mathrm{m}$, sets of four consecutive brain slices were collected, for immunofluorescence, until an anterior-posterior coordinate of $-2.4 \mathrm{~mm}$ (from Bregma) was reached.

\section{Immunolabelling}

BrdU labelling and BrdU/NeuN double-labelling: Brain slices were washed (PBS), then DNA was denatured with $2 \mathrm{~N} \mathrm{HCl}$ for 20 min at $37^{\circ} \mathrm{C}$, subsequent neutralisation with $0.1 \mathrm{M}$ borax buffer (pH9) was $20 \mathrm{~min}$ at room temperature. Then, tissue was incubated with $10 \%$ fetal calf serum for $1 \mathrm{~h}$ RT. Primary antibodies (rat anti-BrdU, AbD Serotec, UK, 1:300; mouse anti-NeuN, Chemicon, Cork, Ireland, 1:500 or mouse anti-BrdU, BD Bioscience, UK, 1:100) were diluted in blocking solution. Primary antibodies were incubated overnight at $4^{\circ} \mathrm{C}$. The respective secondary antibodies (goat anti-rat 488 , goat antimouse 568; goat anti-mouse 488, goat anti-rabbit 568, all Molecular Probes (Oregon, USA), 1:1,000 in blocking solution) were added for $2 \mathrm{~h}$ at room temperature following washing.

Doublecortin labelling: Brain slices were permeabilised with $0.1 \%$ Triton X-100/PBS for $15 \mathrm{~min}$ on ice for DCX labelling procedures. Following PBS washes, slices were blocked in 5\% horse serum and $0.3 \%$ Triton X-100/PBS for $30 \mathrm{~min}$ at room temperature. Slices were washed in PBS and goat anti-DCX antibody (Santz Cruz, 1:100, Santa Cruz Biotech, Germany) was applied in blocking solution overnight at $4{ }^{\circ} \mathrm{C}$. After washing, the secondary antibody, donkey-anti-goat rhodamine conjugated (Jackson Immunoresearch, USA, 1:1,000) was applied for $2 \mathrm{~h}$ at room temperature followed by PBS washes.

BrdU and doublecortin double-labelling: A combination of the protocols was used for the double-labelling of BrdU and doublecortin (DCX). Brain slices were stained for DCX using goat anti-DCX and donkey-anti-goat fluorescein conjugated antibodies. Following washing, slices were then prepared for BrdU labelling and mouse antiBrdU (BD Bioscience, 1:100) was used as primary antibody and goat anti-mouse 568 (Molecular probes, 1:1,000) was used as secondary antibody. Slices were embedded in DAPI-containing mounting media or incubated with Hoechst 33342, and then washed and mounted in FluorSave Reagent (Calbiochem, Merck Bioscience, UK). Control experiments were performed by incubation with secondary antibodies only and no unspecific staining was observed.

\section{Data collection and statistical analysis}

Following sectioning and immunolabelling, cell counts were performed using an Eclipse TE300 inverted microscope (Nikon) and X40 oil objective. BrdU-, DCX-positive cells or cells double positive for BrdU and DCX or NeuN were counted in the DG of the hippocampus. In accordance with our previous work [14], only cells within the subgranular zone and the granule cell layer were included; cells lacking direct contact with the DG (located within the hilus) were excluded from counting. In each case, 6-9 sections were analysed and results presented as number per $10 \mu \mathrm{m}$ coronal section. All cell counts were performed in a blinded fashion, with the counter unaware of the experimental conditions.

Statistical analysis was performed in multiple ways depending on the situation and parameters (SPSSv15, IBM). Data were tested for normal distribution using the Shapiro-Wilk test of normality. For parametric data one-way ANOVA with post-hoc Tukey's test was used, whereas for non-parametric data the Mann-Whitney U-test with a Bonferroni correction was used. All data are presented as mean \pm SEM and statistical significance was considered with $\mathrm{p} \leq 0.05$.

\section{Results}

Following surgery and perfusion, we quantified the generation of new cells in the DG in sections at the respective time points. Notably, in wt animals the NMDA-induced insult resulted in an expected and significantly increased generation of new cells only one day after the last BrdU injection when compared to control animals that did not receive NMDA [Figures 2A, B, short term, control 14.8 \pm 0.8 ( $\mathrm{n}=4$ animals) vs. NMDA 29.2 \pm 0.8 ( $\mathrm{n}=6$ animals) BrdU positive cells $/ 10 \mu \mathrm{m}$ brain section, $\mathrm{p}=0.02$ ] After long-term survival, a decreased number of BrdU-positive cells in both groups (NMDA and control) was noted, and no significance was reached between NMDA and control [control 9.6 \pm 0.7 ( $\mathrm{n}=4$ animals) vs. NMDA 16.2 \pm 3 ( $\mathrm{n}=6$ animals) BrdU-positive cells $/ 10 \mu \mathrm{m}$ brain section; Figures $2 \mathrm{~B}$, D]. In puma knock-out mice, like in the wild-type, treatment with NMDA resulted in significantly increased precursor cell numbers one day after BrdU-injection [control 22.8 \pm 1.9 ( $\mathrm{n}=4$ animals) vs. NMDA 39.5 \pm 5.3 ( $\mathrm{n}=6$ animals) BrdU-positive cells/ $10 \mu \mathrm{m}$ brain section, $\mathrm{p}=0.01$ ] (Figures $2 \mathrm{C}$, D). Interestingly, in the NMDA treated groups BrdU-positive cell numbers decreased to control levels seven days after BrdU injections [NMDA one day $39.5 \pm 5.3$ ( $\mathrm{n}=6$ animals) vs. NMDA seven days $22.7 \pm 1.2$ ( $\mathrm{n}=6$ animals) BrdU-positive cells $/ 10 \mu \mathrm{m}$ brain section, $\mathrm{p}=0.02]$ suggesting that puma-deficiency did not protect the surplus of newly generated cells from dying (Figures 2B, D).

To correlate the increased proliferation to a potential increase in neurogenesis, we used the neuronal progenitor cell marker doublecortin (DCX) and determined DCX-positive cells in the dentate gyrus. Within the shortterm group, significantly increased numbers of DCX-positive cells were counted following NMDA treatment in wt animals (control $73.7 \pm 2.6$ vs. NMDA 139.4 \pm 1.9 DCX-positive cells $/ 10 \mu \mathrm{m}$ brain section, $\mathrm{p}=0.05$; Figure $3 \mathrm{~A}$, B). Our results suggested that NMDA-induced excitotoxicity increased neurogenesis. Following long-term survival, wt NMDA-treated animals showed an elevated level 

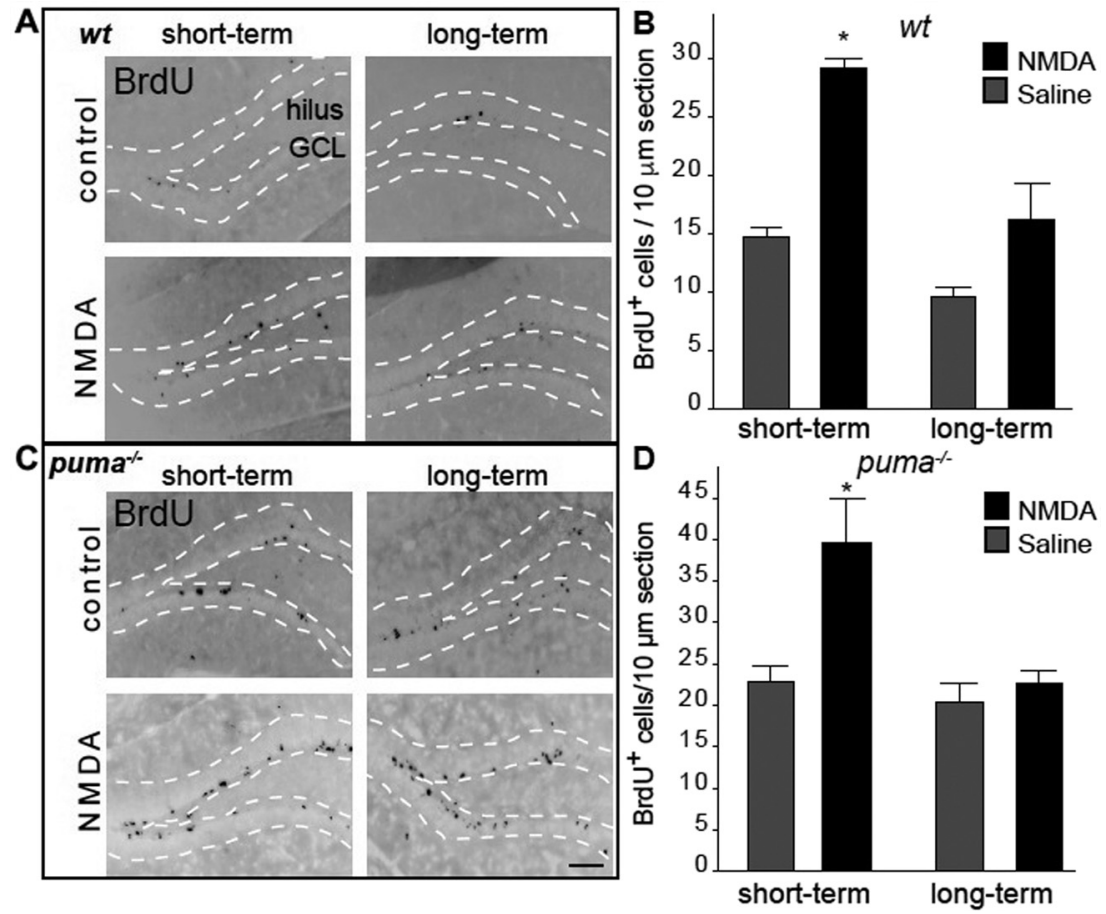

Figure 2: Proliferation and survival of newly generated cells in the DG after NMDA-induced injury. Wt animals and puma ${ }^{-/-}$were subjected to intrahippocampal NMDA or saline administration. Daily BrdU injections $(50 \mathrm{mg} / \mathrm{kg}$, i.p.) at day 6-9 after NMDA treatment and transcardial perfusion one day (short-term survival group) or seven days (long-term survival group) after the last BrdU injection were performed. Following immunolabelling, $10 \mu \mathrm{m}$ brain sections were assessed for BrdU-incorporation into newly generated cells in the DG (A, C, white lines demarcate the blades of the DG). The number of BrdU+cells were counted and compared between the different groups (B, D). Note the significant increase in BrdU+cells in wt and puma ${ }^{-1-}$ mice following intrahippocampal NMDA injections in the short-term survival groups compared to control treated animals of both genotypes. After long-term survival the number of BrdU+cells had decreased in NMDA and control treated wt animals with no significant difference between the two groups. In the puma ${ }^{-/-}$animals no difference in the number of BrdU+cells comparing control animals from the short-term survival group to the long-term survival group was found. BrdU cell numbers after NMDA treatment had decreased in the long-term survival group to the level of cell numbers from control animals. $n=4$ animals for all control groups, $n=6$ for all NMDA treatment groups. Scale bar in (A, C) $200 \mu \mathrm{m}$. GCL, granule cell layer. Error bars represent SEM. * $\mathrm{p} \leq 0.05$.

of DCX-positive cell numbers compared to control (control 78.9 \pm 5.4 vs. NMDA $98.1 \pm 3.5$ DCX-positive cells $/ 10 \mu \mathrm{m}$ brain section, $\mathrm{p}=0.05$; Figure $3 \mathrm{~B}$ ). Their DCX cell number however was already decreased when contrasted to the NMDA-treated/short-term survival group (NMDA shortterm survival $139.4 \pm 2.6$ vs. NMDA long-term survival 98.1 \pm 3.5 DCX-positive cells $/ 10 \mu \mathrm{m}$ brain section, $\mathrm{p}=0.05$; Figure 3B). Even though neurogenesis in the injury group was still heightened long-term after injury, neurogenesis was decreased compared to the earlier NMDA treatment time point, suggesting that the increased level of early neurons could not be maintained. Next, we examined DCX-positive cells in the puma knockouts. Within the short-term survival group the number of DCX-positive cells was significantly increased after NMDA treatment compared to control-treated animals (control $121.6 \pm 8.2 \mathrm{vs}$. NMDA 201.1 \pm 12.5 DCX-positive cells $/ 10 \mu \mathrm{m}$ brain section, $\mathrm{p}=0.01$ ) suggesting that neurogenesis was not impaired by puma ablation (Figure 3C, D). However, the number of
DCX-positive cells had decreased to control levels during the long-term survival, similarly to the effect observed by BrdU cell counts (NMDA/10 days 201.1 \pm 12.5 vs. NMDA/ 16days $120.7 \pm 8.8$ DCX-positive cells $/ 10 \mu \mathrm{m}$ brain section, $\mathrm{p}=0.01$; Figure 3D). It appeared from these results that the deficiency in puma could not protect early neurons generated as a consequence of NMDA-induced injury.

Finally, we analysed whether neuronal development was influenced in the newly generated cells after NMDA-induced excitotoxicity, using BrdU and DCX colabelling (Figure 4A, B). One day after the last BrdU injection, $83-89 \%$ of BrdU-positive cells expressed the neuronal progenitor cell marker DCX in both control as well as NMDA-treated animals, suggesting that BrdU was incorporated within the same percentage of progenitor cells (Figure 4C). These numbers were approximately halved in the long-term control survival group, in shamtreated animals (wt and puma $^{-/-}$) 39\% of the BrdU positive cells still expressed DCX (Figure 4C). In contrast following 

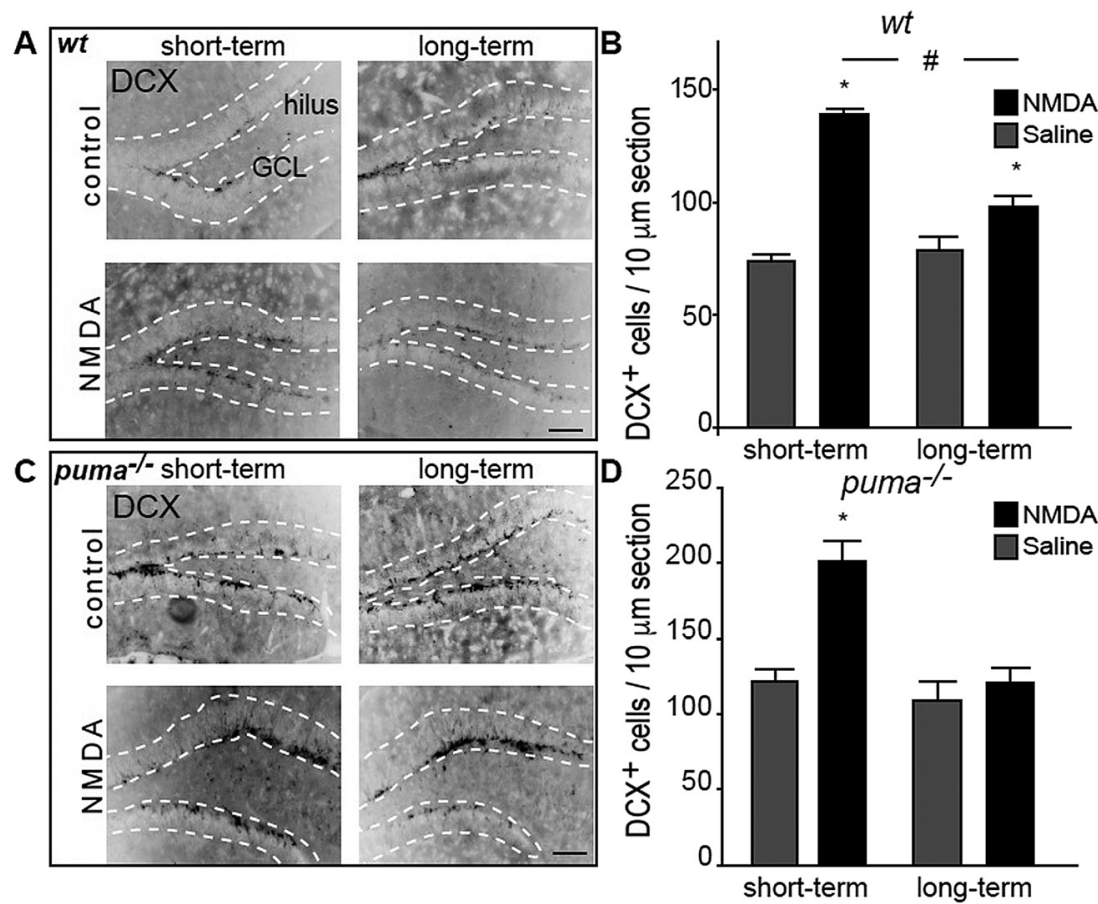

Figure 3: Neurogenesis and survival of newly generated cells in the DG after NMDA-induced injury. Wt animals and puma $^{-/-}$animals were subjected to intrahippocampal NMDA or saline administration followed by transcardial perfusion at shortterm survival and long-term survival time points. Ten micrometre brain sections were assessed by anti-DCX immunohistochemistry $(A, C$, white lines demarcate the blades of the DG). DCX+cells were counted and compared between the different groups $(B, D)$. $D C X+$ cells were significantly more following NMDA treatment in both groups (short and long-term survival). Cell numbers decreased significantly from day 10-16 after NMDA treatment (wt, D). In puma ${ }^{-1-}$ animals the number of $D C X+$ cells was significantly increased short-term after NMDA administration but the numbers were decreased to control levels at the long-term survival time point (D). $n=4$ animals for all control groups, $\mathrm{n}=6$ for all NMDA treatment groups. Scale bar in (A, B) $200 \mu \mathrm{m} . \mathrm{GCL}$, granule cell layer. Error bars represent SEM. ${ }^{*} \mathrm{p} \leq 0.05$.
NMDA treatment, between 54\% (wt) and 65\% $\left(\right.$ puma $\left.^{-/-}\right)$of the BrdU cells were positive for DCX (Figure 4C). Interestingly, a trend towards significance was observed only for the puma $^{-/-}$mice (control 39\% vs. NMDA65\% BrdU to BrdU/DCX cells, $\mathrm{p}=0.072$ )

In order to determine if neuronal maturation was influenced in the newly generated cells after NMDA-induced excitotoxicitywe performed co-labelling with BrdU and the post-mitotic marker NeuN (Figures 5A, B). Again, double-labelled cells were assessed within the DG. Following short-term survival (10 days after excitotoxic insult), only a small percentage of BrdU-positive cells already expressed NeuN (16-18\%; Figure 5C), reflecting the short-time window. However, the majority of BrdU cells expressed NeuN a week later (77-88\%; Figure 5D). There was no difference in the proportion of BrdU/NeuN-positive cells comparing the different genotypes and treatments within the two analysed time points. These results suggested that phenotypic fate of the cells was preserved regardless of genotype and treatment (control vs. NMDA).

\section{Discussion}

We examined the role of the BH3-only protein Puma in proliferation and survival of newly generated cells within the DG following an excitotoxic insult to the hippocampal CA1 subfield. We explored whether puma-deficiency influenced the NMDA-induced up-regulation of proliferation and/or the subsequent death of these cells. While neurogenesis was upregulated in wild-type and puma-deficient animals following NMDA-induced excitotoxicity to the hippocampal CA1 subfield, the gene knock-out could not rescue this surplus of newly generated cells from subsequent apoptotic cell death. These results are different from earlier work, whereby we demonstrated the lack of the BH3-only protein Puma significantly increased the survival of neuronal progenitor cells, though their proliferation was unaffected in naïve animals [9]. Similar results have been observed in hematopoietic multipotent progenitors [24]. These differences are likely due to the stimulating event, in this case an excitotoxic insult.

We found higher numbers of BrdU and doublecortinpositive cells in Puma-deficient mice, concurrent with our previous results [9]. Interestingly, it has also been shown that telencephalic ventricular zone neuronal precursor cells (NPCs) were protected from AraC-induced cell death in puma-heterozygous animals [23]. Puma is a BH3-only protein and potent mediator of the intrinsic, mitochondrial pathway of apoptosis. It either activates Bax or Bak with mitochondrial outer membrane pore formation, or it sequesters the anti-apoptotic members of the Bcl-2 family [25]. Puma, potently activated in neurons following 

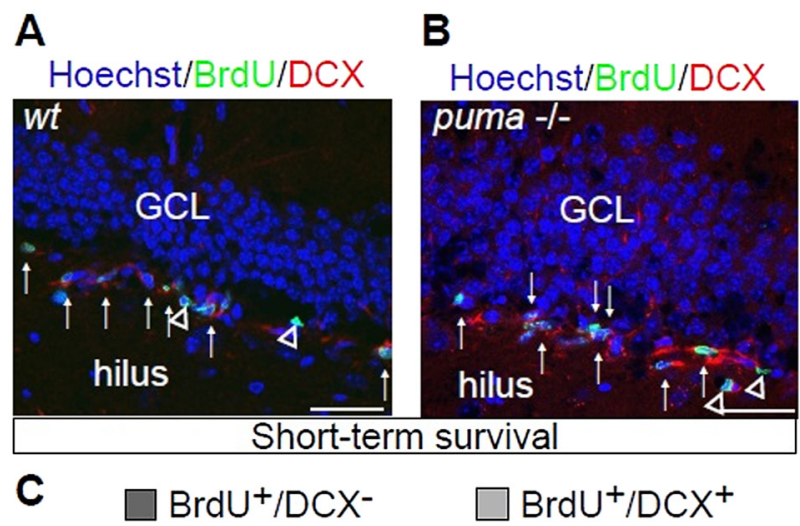

$\square \mathrm{BrdU}^{+} / \mathrm{DCX}+$

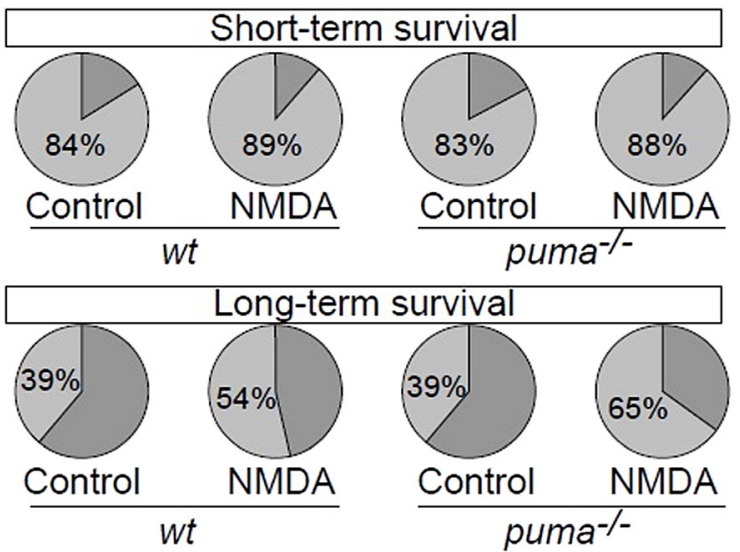

Figure 4: BrdU and DCX co-labelling in the dentate gyrus after NMDA-induced excitotoxicity. Wt animals and mice deficient in puma were subjected to intrahippocampal NMDA or saline administration. Daily BrdU injections $(50 \mathrm{mg} / \mathrm{kg}$, i.p.) at day 6-9 after NMDA treatment and transcardial perfusion one day (short-term survival group) or seven days (long-term survival group) after the last $\mathrm{BrdU}$ injection were performed. Ten $\mu \mathrm{m}$ brain sections were assessed for BrdU and DCX expression. In the short-term survival group the majority of BrdU-incorporated cells expressed DCX in both wt and puma ${ }^{-/-}$animals. Arrows point at double-labelled cells, open arrowheads at BrdU+/DCX-cells (A, B). In the long-term group only $39 \%$ of BrdU+cells still expressed DCX in control groups of wt and puma $^{-/-}$mice. NMDA treatment increased the proportion of $\mathrm{BrdU}+/$ $D C X+$ cells to $54 \%$ in wt animals and $65 \%$ in puma ${ }^{-/-}$mice, this effect did not reach significance (C). Scale bar in (A, B) $50 \mu \mathrm{m}$. GCL, granule cell layer.

endoplasmic reticulum stress [26], is required for ER-stress induced apoptosis [27], but not for cell death following NMDA-mediated toxicity [22]. Puma also controls cell death induced by trophic factor withdrawal in neurons [28]. Importantly, suppression of neuronal electrical activity by NMDA-receptor blockers resulted in Puma-dependent apoptosis under trophic factor withdrawal [29]. Common to these cellular stress conditions is that pro-apoptotic Puma expression is induced by Foxo3a [30]. Foxo3a is expressed in neuronal precursor cells under basal conditions and positively regulates precursor cell numbers

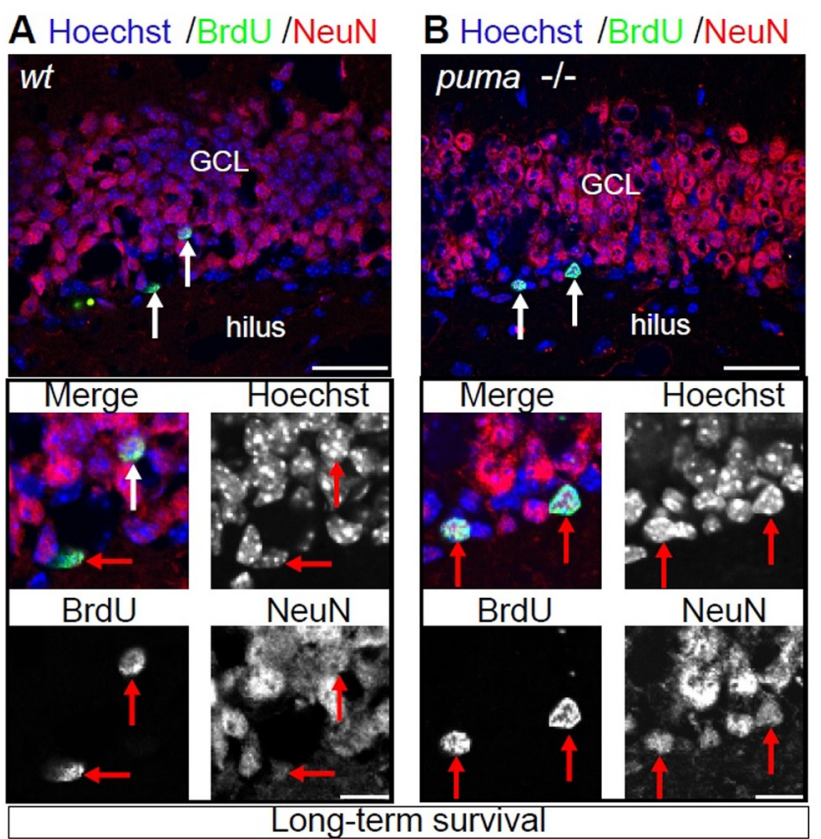

C

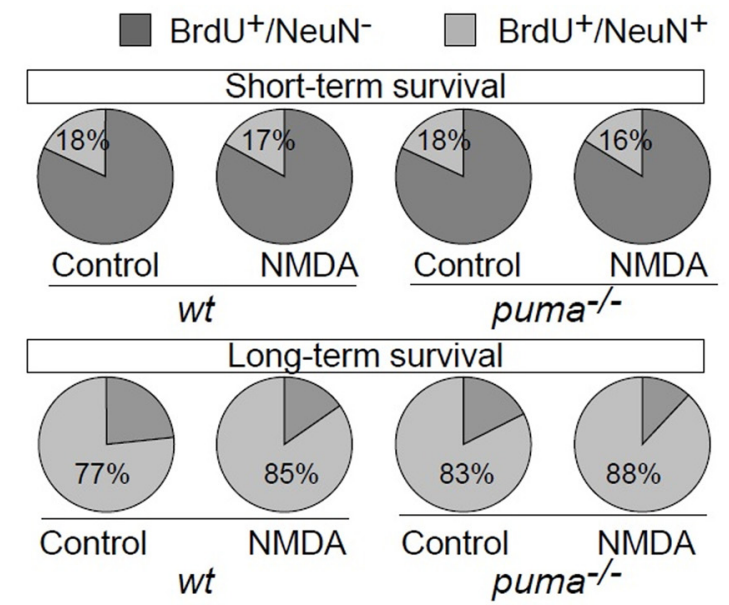

Figure 5: BrdU and NeuN co-labelling in the dentate gyrus after NMDA-induced excitotoxicity. Wt animals and puma $^{-1-}$ mice received intrahippocampal NMDA or saline and daily BrdU injections (50 mg/kg, i.p.) at day 6-9 after NMDA. Transcardial perfusion one day (short-term survival group) or seven days (long-term survival group) after the last BrdU injection was performed. Ten micro metre brain sections were assessed for BrdU and NeuN (A, B). One day following the last BrdU injection only around $18 \%$ of BrdU+cells expressed NeuN. Seven days after the last BrdU injection (long-term survival group), the majority of BrdU-incorporated cells expressed NeuN in both wt and puma ${ }^{-/-}$animals (C). There was no difference in the proportion of $\mathrm{BrdU}+/ \mathrm{NeuN}$ - to $\mathrm{BrdU}+/ \mathrm{NeuN}+$ cells (C lower row). White arrows in (A) and (B) point at $\mathrm{BrdU}+/ \mathrm{NeuN}+$ cells magnified below. There was no difference between genotypes and treatment groups (C upper row). Scale bar in (A, B) $50 \mu \mathrm{m}$. GCL, granule cell layer.

[31, 32], Foxo3a may be diverted to gene promoters unrelated to pro-apoptotic proteins in Puma knock-out mice. Tran-

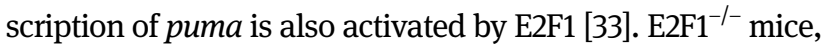


similarly to our previous study on bim and $\mathrm{puma}^{-/-}$mice [9], show decreased levels of apoptosis [34] suggesting that E2F1-induced transcription of puma might be responsible for the death of newly generated cells within the hippocampus. Overall, as there currently is no evidence that Puma directly affects the cell cycle, it may be assumed that the protective effects of Puma-deficiency on neuronal precursor cells is due to their protection from apoptotic cell death [35, 9].

In this study the $\mathrm{puma}^{-/-}$animals used represent a global knock-out model where puma is lacking in all cells, including NSPCs $[23,36]$. puma $^{-/-}$mice were generated from ES cells that lacked puma exons 2 and 3, which encompass the start site and the $\mathrm{BH} 3$ region of puma. However, indirect effects of puma gene deletion in other cell types such as neurons, cannot be excluded and may have impacted on NPC survival. Apoptotic cells secrete factors that stimulate cell proliferation and may regulate survival in neighbouring cells, e.g. through the WNT/betacatenin pathway (reviewed in [37]). However a deficiency in puma in non-NPCs would potentially limit such paracrine signalling. It is also possible that the lack of puma in nonNPCs switches their cell death to a more necrotic phenotype, which in turn may activate inflammatory processes.

NMDA injections up-regulated proliferating precursor cells and neurogenesis. Inhibitors of NMDA-receptor signalling increase the density of the granule cell layer [38, 39]. Physiological concentrations of glutamate were thus suggested to limit neurogenesis. Excitotoxic levels of glutamatereceptor agonists were previously shown to stimulate neurogenesis in the dentate gyrus [13, 40]. Glutamate-responsive NMDA-receptors are expressed on proliferating cells of the adult subgranular zone of the dentate gyrus [41] and their positive influence on neurogenesis seems to involve CaMKIV-dependent CREB signalling [42]. Importantly, the transcription factor CREB currently emerges centre-stage as a positive regulator of neurogenesis [43]. Synaptic activity is a potent activator of CREB while suppressing pro-apoptotic protein Puma expression [29]. Puma is mainly activated by transcriptional mechanisms. While CREB-responsive elements can be found in the Puma-promoter [44], these two proteins may be regulated contrariwise following an NMDA-stimulus to neural precursor cells.

Analysis of proliferation and survival of the newly generated cells within the DG of $w t$ mice revealed that while proliferation was significantly increased short-term following NMDA treatment, those cells did not survive an additional week and apoptotic cell death most likely accounted for the reduced cell numbers. Thus, Pumadeficiency failed to protect the new precursor cells and newly formed neurons from cell death. In fact, when cell death was calculated for BrdU-positive cells and compared between control and NMDA treated animals, in control animals about $66 \%$ of the cells had survived an additional week, but only $53 \%$ of the BrdU-positive cells were still present at this time point in animals subjected to intrahippocampal NMDA injection. This is in agreement with a study by Takasawa and colleagues who showed that brain injury increased proliferation, but also decreased the survival to $20 \%$ of the newly generated cells compared to control animals where $90 \%$ of the cells survived [45].

Interestingly, a similar effect was also observed in the DG of puma $^{-1-}$ mice. Within the control treated animals no decrease in the number of BrdU-positive cells was detected following an additional week of survival, suggesting that the lack in Puma protected those cells from apoptotic cell death, as previously observed [9]. However, in puma $^{-/-}$animals with intrahippocampal NMDA injection, a decrease of BrdUpositive cells, to control levels, following long-term survival was detected, suggesting that deficiency in puma did not protect the newly generated cells following injury. A similar observation was found for doublecortin-positive precursors. It is also possible that other pro-apoptotic BH3-only proteins such as Bcl-rambo control the survival of NPCs, particularly in the absence of puma [46].

BrdU/DCX-double positive NPC's were numerically higher in Puma-knockout DG following injury in the longterm survival, but this effect was not statistically significant. BrdU/NeuN-positive neuron numbers were also not significantly higher in Puma-deficient compared to wild-type animals in the long-term survival group following NMDA. It has been described that there is a transition of DCX to NeuN expression during neuronal maturation, during an intermediate state both markers are expressed. Our data cautiously suggest that more of the new cells generated under the influence of NMDA-induced injury were still in this intermediate state, whereas more cells of control animals had already matured into neurons. In a previous study the time course of neuronal maturation after ischemia was similar to that under normal conditions [47, 48]. However, Tanaka and co-workers (2004) conducted their study using gerbils, GFP-retrovirus injection and a transient global ischemia model, while in our study back-crossed C57BL/6 mice, BrdU injection and a model of excitotoxicity were used. These variables may account for the differences observed in neuronal maturation following brain injury. Supporting our study, similar decelerated maturation of newly generated cells within the hippocampus has been demonstrated in the aged brain [49], though the molecular mechanisms responsible are yet to be uncovered.

We previously showed Puma-deficient neurons are not protected from excitotoxic cell death and similar sizes of lesions are produced in wild type and Puma-deficient mice 
[22]. A delayed release of endogenous glutamate stores, on already differentiated neurons as a sequela to NMDA-injury, is expected to have a similarly excitotoxic effect in both genotypes. On the other hand trophic signalling following glutamate-receptor activation may underlie the minimal increase in BrdU/NeuN doublepositive neurons in the long-term survival group across the genotypes and treatment. In newly-born cells, differential sets of growth and transcription factors may have been activated. We show that such pathways are Puma independent, with unfavourable outcomes for the survival of the newborn cells regardless of the genotype. On the contrary, decreased neuronal differentiation could also have affected the survival of the newly generated cells, since it has been suggested that forming functional connections and integrating into the existing network is necessary for the survival of the cells [50]. Therefore, decreased neuronal maturation could have contributed to the decrease of cell survival within the DG also under Pumadeficient conditions. As the same amount of BrdU-positive cells expressed the neuronal marker NeuN one week following the last BrdU administration the phenotypic fate seems to be preserved among different genotypes ( puma $^{-/-}$ and $w t$ ) which is consistent with observations by others [1].

One potential limitation of this study was the use of only male mice. While the impact of gender on physiology and behaviour is important, the intention of this study was to examine the effect of PUMA knockout on the survival regeneration and survival of cells following an acute excitotoxic injury. Oestradiol has been consistently shown to exhibit neuroprotective activities and there is evidence that this is mediated, at least partly, through the NMDA receptor [51]. Hence the use of female mice in this study would have introduced significant variability due to the stage of oestrus cycle and potentially reduced the chances of detecting an effect of PUMA knockout. Despite this, it would be important in the future to determine the impact of gender in this paradigm. One other limitation of our study is that we used DCX as a marker for neurogenesis. However it should be mentioned that DCX is also expressed in neural progenitor cells, which frequently undergo apoptosis during the first wave of selection [52]. While we did not perform DCX/NeuN double staining, even DCX/NeuN double positive cells may not survive the second wave of apoptosis when integration into neuronal circuits fails.

\section{Conclusion}

Taken together, we showed that while excitotoxic injury to the hippocampal CA1 subfield increased proliferation in the
DG, those cells could not be protected from subsequent apoptosis in mice deficient in the pro-apoptotic protein Puma, suggesting that Puma is not involved in cell survival of the newly generated cells in response to excitotoxic injury.

Research funding: This research was supported by grants from Science Foundation Ireland to JHMP (08/IN1/1949; $16 / \mathrm{RC} / 3948)$, and by the National Biophotonics and Imaging Platform Ireland (Higher Education Authority).

Author contributions: All authors take responsibility for the integrity of the data and the accuracy of the data analysis. Conceptualization, ECB, BPK and JHMP; Methodology, ECB, HGK and BPK ;Investigation, ECB and HGK; Formal Analysis, ECB, HGK and BPK.; Writing Original Draft, ECB.; Writing - Review \& Editing, ECB, HGK, JHMP, BPK; Supervision, BPK and JHMP; Funding Acquisition, JHMP

Competing interests: None of the authors have a conflict of interest with this paper.

Informed consent: Informed consent was obtained from all individuals included in this study.

Ethical approval: Animal experiments complied with National and European guidelines and were carried out under license from the Department of Health and Children (Ireland). Procedures were reviewed and approved by the Royal College of Surgeons in Ireland (RCSI) Research Ethics Committee (REC134).

\section{References}

1. Sun W, Winseck A, Vinsant S, Park $\mathrm{OH}$, Kim H, Oppenheim RW. Programmed cell death of adult-generated hippocampal neurons is mediated by the proapoptotic gene bax. J Neurosci 2004;24: 11205-13.

2. Pfisterer U, Khodosevich K. Neuronal survival in the brain: neuron type-specific mechanisms. Cell Death Dis 2017;8:e2643.

3. Kim WR, Park OH, Choi S, Choi SY, Park SK, Lee KJ, et al. The maintenance of specific aspects of neuronal function and behavior is dependent on programmed cell death of adult-generated neurons in the dentate gyrus. Eur J Neurosci 2009;29:1408-21.

4. Ryu JR, Hong CJ, Kim JY, Kim EK, Sun W, Yu SW. Control of adult neurogenesis by programmed cell death in the mammalian brain. Mol Brain 2016;9:43.

5. Sahay A, Scobie KN, Hill AS, O'Carroll CM, Kheirbek MA, Burghardt NS, et al. Increasing adult hippocampal neurogenesis is sufficient to improve pattern separation. Nature 2011;472:466-70.

6. Crowther AJ, Gama V, Bevilacqua A, Chang SX, Yuan H, Deshmukh $M$, et al. Tonic activation of Bax primes neural progenitors for rapid apoptosis through a mechanism preserved in medulloblastoma. J Neurosci 2013;33:18098-108.

7. Kuhn HG, Biebl M, Wilhelm D, Li M, Friedlander RM, Winkler J. Increased generation of granule cells in adult Bcl2-overexpressing mice: a role for cell death during continued hippocampal neurogenesis. Eur J Neurosci 2005;22:1907-15. 
8. Willis SN, Chen L, Dewson G, Wei A, Naik E, Fletcher Jl, et al. Proapoptotic Bak is sequestered by $\mathrm{Mcl}-1$ and $\mathrm{Bcl}-\mathrm{xL}$, but not Bcl2, until displaced by BH3-only proteins. Gene Dev 2005;19: 1294-305.

9. Bunk EC, Konig HG, Bernas T, Engel T, Henshall DC, Kirby BP, et al. $\mathrm{BH} 3-o n l y$ proteins BIM and PUMA in the regulation of survival and neuronal differentiation of newly generated cells in the adult mouse hippocampus. Cell Death Dis 2010;1:e15.

10. Kempermann G, Kuhn HG, Gage FH. More hippocampal neurons in adult mice living in an enriched environment. Nature 1997;386: 493-5.

11. van Praag H, Kempermann G, Gage FH. Running increases cell proliferation and neurogenesis in the adult mouse dentate gyrus. Nat Neurosci 1999;2:266-70.

12. Malberg JE, Eisch AJ, Nestler EJ, Duman RS. Chronic antidepressant treatment increases neurogenesis in adult rat hippocampus. J Neurosci 2000;20:9104-10.

13. Parent JM, Yu TW, Leibowitz RT, Geschwind DH, Sloviter RS, Lowenstein DH. Dentate granule cell neurogenesis is increased by seizures and contributes to aberrant network reorganization in the adult rat hippocampus. J Neurosci 1997;17:3727-38.

14. Bunk EC, Konig HG, Prehn JH, Kirby BP. Effect of the N-methylD-aspartate NR2B subunit antagonist ifenprodil on precursor cell proliferation in the hippocampus. J Neurosci Res 2014;92: 679-91.

15. Jin K, Minami M, Lan JQ, Mao XO, Batteur S, Simon RP, et al. Neurogenesis in dentate subgranular zone and rostral subventricular zone after focal cerebral ischemia in the rat. Proc Natl Acad Sci USA 2001;98:4710-5.

16. Zhang RL, Chopp M, Roberts C, Liu X, Wei M, Nejad-Davarani SP, et al. Stroke increases neural stem cells and angiogenesis in the neurogenic niche of the adult mouse. PLoS One 2014;9:e113972.

17. Rice AC, Khaldi A, Harvey HB, Salman NJ, White F, Fillmore H, et al. Proliferation and neuronal differentiation of mitotically active cells following traumatic brain injury. Exp Neurol 2003;183: 406-17.

18. Wang X, Seekaew P, Gao X, Chen J. Traumatic brain injury stimulates neural stem cell proliferation via mammalian target of rapamycin signaling pathway activation. eNeuro 2016;3. https:// doi.org/10.1523/eneuro.0162-16.2016.

19. Cameron HA, Gould E. Adult neurogenesis is regulated by adrenal steroids in the dentate gyrus. Neuroscience 1994;61:203-9.

20. Kempermann G, Kuhn HG, Gage FH. Experience-induced neurogenesis in the senescent dentate gyrus. J Neurosci 1998;18: 3206-12.

21. Liu D, Ou L, Clemenson GD Jr., Chao C, Lutske ME, Zambetti GP, et al. Puma is required for p53-induced depletion of adult stem cells. Nat Cell Biol 2010;12:993-8.

22. Concannon CG, Ward MW, Bonner HP, Kuroki K, Tuffy LP, Bonner $\mathrm{CT}$, et al. NMDA receptor-mediated excitotoxic neuronal apoptosis in vitro and in vivo occurs in an ER stress and PUMA independent manner. J Neurochem 2008;105:891-903.

23. Akhtar RS, Geng Y, Klocke BJ, Latham CB, Villunger A, Michalak EM, et al. BH3-only proapoptotic Bcl-2 family members Noxa and Puma mediate neural precursor cell death. J Neurosci 2006;26: 7257-64.

24. Belle JI, Petrov JC, Langlais D, Robert F, Cencic R, Shen S, et al. Repression of $\mathrm{p} 53$-target gene Bbc3/PUMA by MYSM1 is essential for the survival of hematopoietic multipotent progenitors and contributes to stem cell maintenance. Cell Death Differ 2016;23: 759-75.

25. Yee KS, Vousden KH. Contribution of membrane localization to the apoptotic activity of PUMA. Apoptosis 2008;13:87-95.

26. Reimertz C, Kogel D, Rami A, Chittenden T, Prehn JH. Gene expression during ER stress-induced apoptosis in neurons: induction of the BH3-only protein Bbc3/PUMA and activation of the mitochondrial apoptosis pathway. J Cell Biol 2003;162: 587-97.

27. Kieran D, Woods I, Villunger A, Strasser A, Prehn JH. Deletion of the BH3-only protein puma protects motoneurons from ER stressinduced apoptosis and delays motoneuron loss in ALS mice. Proc Natl Acad Sci USA 104;2007:20606-11.

28. Ambacher KK, Pitzul KB, Karajgikar M, Hamilton A, Ferguson SS, Cregan SP. The JNK- and AKT/GSK3beta- signaling pathways converge to regulate Puma induction and neuronal apoptosis induced by trophic factor deprivation. PLoS One 2012;7:e46885.

29. Leveille F, Papadia S, Fricker M, Bell KF, Soriano FX, Martel MA, et al. Suppression of the intrinsic apoptosis pathway by synaptic activity. J Neurosci 2010;30:2623-35.

30. You H, Pellegrini M, Tsuchihara K, Yamamoto K, Hacker G, Erlacher $\mathrm{M}$, et al. FOXO3a-dependent regulation of Puma in response to cytokine/growth factor withdrawal. J Exp Med 2006; 203:1657-63.

31. Renault VM, Rafalski VA, Morgan AA, Salih DA, Brett JO, Webb AE, et al. FoxO3 regulates neural stem cell homeostasis. Cell Stem Cell 2009;5:527-39.

32. Paik JH, Ding Z, Narurkar R, Ramkissoon S, Muller F, Kamoun WS, et al. FoxOs cooperatively regulate diverse pathways governing neural stem cell homeostasis. Cell Stem Cell 2009;5:540-53.

33. Hershko T, Ginsberg D. Up-regulation of Bcl-2 homology 3 (BH3)only proteins by E2F1 mediates apoptosis. J Biol Chem 2004;279: 8627-34.

34. Cooper-Kuhn CM, Vroemen M, Brown J, Ye H, Thompson MA, Winkler J, et al. Impaired adult neurogenesis in mice lacking the transcription factor E2F1. Mol Cell Neurosci 2002;21:312-23.

35. Yu J, Yue W, Wu B, Zhang L. PUMA sensitizes lung cancer cells to chemotherapeutic agents and irradiation. Clin Canc Res 2006;12: 2928-36.

36. Villunger A, Michalak EM, Coultas L, Mullauer F, Bock G, Ausserlechner MJ, et al. p53- and drug-induced apoptotic responses mediated by $\mathrm{BH} 3-o n l y$ proteins puma and noxa. Science 2003;302:1036-8.

37. Boland K, Flanagan L, Prehn JH. Paracrine control of tissue regeneration and cell proliferation by Caspase-3. Cell Death Dis 2013;4:e725.

38. Cameron HA, McEwen BS, Gould E. Regulation of adult neurogenesis by excitatory input and NMDA receptor activation in the dentate gyrus. J Neurosci 1995;15:4687-92.

39. Nacher J, Alonso-Llosa G, Rosell DR, McEwen BS. NMDA receptor antagonist treatment increases the production of new neurons in the aged rat hippocampus. Neurobiol Aging 2003;24:273-84.

40. Bunk EC, Konig HG, Bonner HP, Kirby BP, Prehn JH. NMDA-induced injury of mouse organotypic hippocampal slice cultures triggers delayed neuroblast proliferation in the dentate gyrus: an in vitro model for the study of neural precursor cell proliferation. Brain Res 2010;1359:22-32.

41. Nacher J, Varea E, Miguel Blasco-Ibanez J, Gomez-Climent MA, Castillo-Gomez E, Crespo C, et al. N-methyl-d-aspartate receptor 
expression during adult neurogenesis in the rat dentate gyrus. Neuroscience 2007;144:855-64.

42. Li M, Zhang DQ, Wang XZ, Xu TJ. NR2B-containing NMDA receptors promote neural progenitor cell proliferation through CaMKIV/ CREB pathway. Biochem Biophys Res Commun 2011;411:667-72.

43. Ortega-Martinez $\mathrm{S}$. A new perspective on the role of the CREB family of transcription factors in memory consolidation via adult hippocampal neurogenesis. Front Mol Neurosci 2015;8:46.

44. Luo X, He Q, Huang Y, Sheikh MS. Cloning and characterization of a 553 and DNA damage down-regulated gene PIQ that codes for a novel calmodulin-binding IQ motif protein and is up-regulated in gastrointestinal cancers. Canc Res 2005;65:10725-33.

45. Takasawa K, Kitagawa K, Yagita Y, Sasaki T, Tanaka S, Matsushita $\mathrm{K}$, et al. Increased proliferation of neural progenitor cells but reduced survival of newborn cells in the contralateral hippocampus after focal cerebral ischemia in rats. J Cerebr Blood Flow Metabol 2002;22:299-307.

46. Schouten M, Fratantoni SA, Hubens CJ, Piersma SR, Pham TV, Bielefeld $P$, et al. MicroRNA-124 and - 137 cooperativity controls caspase-3 activity through BCL2L13 in hippocampal neural stem cells. Sci Rep 2015;5:12448.
47. Tanaka R, Yamashiro K, Mochizuki H, Cho N, Onodera M, Mizuno $\mathrm{Y}$, et al. Neurogenesis after transient global ischemia in the adult hippocampus visualized by improved retroviral vector. Stroke; J Cereb Circ 2004;35:1454-9.

48. van Praag H, Schinder AF, Christie BR, Toni N, Palmer TD, Gage FH. Functional neurogenesis in the adult hippocampus. Nature 2002; 415:1030-4.

49. Rao MS, Hattiangady B, Abdel-Rahman A, Stanley DP, Shetty AK. Newly born cells in the ageing dentate gyrus display normal migration, survival and neuronal fate choice but endure retarded early maturation. Eur J Neurosci 2005;21:464-76.

50. Tao HW, Poo MM. Activity-dependent matching of excitatory and inhibitory inputs during refinement of visual receptive fields. Neuron 2005;45:829-36.

51. Liu SB, Zhao MG. Neuroprotective effect of estrogen: role of nonsynaptic NR2B-containing NMDA receptors. Brain Res Bull 2013;93:27-31.

52. Sierra A, Encinas JM, Deudero JJ, Chancey JH, Enikolopov G, Overstreet-Wadiche LS, et al. Microglia shape adult hippocampal neurogenesis through apoptosis-coupled phagocytosis. Cell Stem Cell 2010;7:483-95. 